\title{
Is sensible medicine a virtuous approach as an antidote against immediate action pressure on physicians?
}

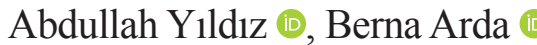 \\ Department of History of Medicine and Ethics, Ankara University School of Medicine, Ankara, Turkey
}

The coronavirus disease 2019 (COVID-19) pandemic has affected humanity in numerous ways. Without a doubt, the health system is one of the most affected areas, and its members have found themselves being forced to take immediate action. In this context, phrases, such as health army and warriors, have frequently been attributed to healthcare workers and physicians. ${ }^{1}$ Undoubtedly, this discourse has a reflection on the meaning of the world of the healthcare workers. These references may be effective on actions that individuals take during crises. $^{2}$

Physicians are obliged to act on the basis of their knowledge in case of emergency, and this obligation is a moral and a professional one with certain exceptions. However, is there a difference between a physician's feeling of obligation to act in an emergency and their need to act? New situations, such as the COVID-19 pandemic, indicate that there may be such a difference. The likelihood of such a difference increases particularly when data and knowledge are insufficient. Such shortfalls are usually compensated for by different types of content. Indeed, during the COVID-19 pandemic, almost anyone, whether they had sufficient knowledge of the scientific aspect of the issue or not, has made suggestions without sufficient scientific evidence. Some accuse physicians of insufficient action, whereas others accuse them of giving unnecessary treatments. So, how should a healthcare worker, who is referred to as a warrior, act in this sort of situation?

The pandemic brought the vitality of these questions to light. Whereas we were considering these questions, we came across the concept of sensible medicine in an article entitled "Sensible Medicine-Balancing Intervention and Inaction During the COVID-19 Pandemic" published by Christopher Seymour et al. in the November 2020 issue of the Journal of the American Medical Association. ${ }^{3}$ In addition to its medically informative reference, we consider the concept of sensible medicine as a useful one that should be discussed in terms of the philosophy of medicine and ethics. In particular, we believe that this particular concept has an extremely crucial world of meaning not only because it may have a strict relationship with the ethics of virtue beyond its factual aspect that points to moderation but also because it refers to moderation between not doing any harm and providing benefit in terms of different contexts and approaches. Thus, it would be useful to consider that this concept can be regarded as a virtue that can guide a warrior. Moreover, the philosophical and ethical basis of practical scientific approaches is worth analyzing.

\section{What is Sensible Medicine?}

The natural response of physicians has been to take immediate action during the pandemic. Particularly with patients facing fatal risks, physicians have been taking decisive actions and making a difference in the course of this global situation. This condition is somewhat associated with their usual urge to opt for action over inaction. $^{3}$

In cases when standardized information is available and the action plans for emergency situations are clear, usually, no disparity is noted between impulses and the decisions of physicians because their attitudes significantly coincide with reality. However, the critical question should be what should be our attitude in cases where knowledge and insights regarding an emergency situation are not clearly defined? Physicians face the question of what to do if adequate knowledge, medication, and tools are not available for treatment. Should physicians take action when they are supposed to stick to the evaluation process and supportive treatment? Seymour et al. ${ }^{3}$ discussed this question in the context of the COVID-19 pandemic and highlighted that physicians were experiencing a tension between intervening and refraining from the intervention for evaluation purposes. In this context, some of the clinicians have adopted a hawkish attitude and have been eager to put new knowledge and treatments into action to save patients. For this condition, their skepticism has decreased, and their tendency toward treatment has increased. This tendency can be attributed to an unconscious bias that ignores methodological problems and favors action. In stark contrast to this bias, a state of skepticism and despair of interventions amounting to nihilism on almost every new method can also be noted. The nihilist is almost confident that the treatment will be ineffective and useless. In the face of these 2 extreme approaches,

Address for Correspondence: Berna Arda, Department of History of Medicine and Ethics, Ankara University School of Medicine, Ankara, Turkey

e-mail: Berna.Arda@medicine.ankara.edu.tr

Received: January 14, 2021 Accepted: January 21, 2021 • DOI: 10.5152/balkanmedj.2021.21090

Available at www.balkanmedicaljournal.org

ORCID iDs of the authors: A.Y. 0000-0001-5135-7200; B.A. 0000-0003-2043-2444.

Cite this article as:

Yildiz A, Arda B. Is sensible medicine a virtuous approach as an antidote against immediate action pressure on physicians? Balkan Med J. $2021 ; 38(2): 65-67$.

Copyright@Author(s) - Available online at http://balkanmedicaljournal.org/ 
Seymour et al. ${ }^{3}$ argued that sensible medicine would serve patients better than unjustified treatments on the basis of unproven interventions; therefore, they defined the concept of sensible medicine as an approach aiming to search for a balance on a range of evidence for treatment and the transfer of (new) knowledge to the clinic or practice.

Sensible medicine is an optimistic approach that considers that some treatments are effective but suggesting that some caution should be taken into consideration. Regarding this approach, the process of translating new knowledge to the bedside manner, the clinical use is balanced with the existing strong evidence, and negative consequences are avoided. The authors noted that adhering to the approach of sensible medicine has become increasingly difficult during the COVID-19 pandemic and similar situations. This phenomenon is observed because of social expectations and pressures on one hand and the emerging heap of scientific knowledge on the other. This finding may imply that clinicians and scientists may be forced to go astray from time to time in their efforts to completely understand the disease and find a treatment. ${ }^{3}$

The authors presented recommendations to remain within the sensible medicine approach in such cases. These recommendations can be summed up as follows: (1) There is no magical remedy or solution for complex cases, such as COVID-19. (2) Physicians who feel that they must take action in difficult situations should be cautious about it. Sometimes, it may be more beneficial to do little. (3) Maintaining the current treatments and care of patients in the optimal condition is critical in reducing adverse effects. Even if we do not have a magic drug, reducing mortality by treating patients' existing diseases appropriately and providing a good intensive care service is essential. (4) It should be taken into account that even qualified clinical trials conducted in emergency situations, such as COVID-19, may have a bias, and we should focus on studies with high-quality evidence. (5) Care should be taken against the alluring effect of the expression new in new treatment discourses, and caution should be adopted in their translation to the clinical practice. In this context, parameters such as evidence strength, reproducibility, and effectiveness should be considered. ${ }^{3}$

In summary, sensible medicine does not mean inaction. However, one can say that it indicates a calm, moderate, and humble approach to the existing treatments and methods in this process. Sensible medicine encourages clinicians to maintain the current standard treatment in an optimal way, reduce unnecessary interventions, and depend on scientific evidence. Rather than leaving them in a dilemma of action or inaction, it encourages physicians to engage in supportive treatment and invites them to be humble about treatments. ${ }^{3}$

\section{Sensible Medicine as a Virtuous Approach}

Although we assume that the concept or approach of sensible medicine should be inherent in general medical practice, we believe that the concept of sensible medicine, particularly from the perspective considered in this article, is a good mnemonic concept for physicians for emergencies and unforeseen situations. In this context, we believe that the concept has crucial practical implications, particularly in terms of clinical ethics and philosophy of medicine. We would like to note that highlighting these implications would enhance the power of the concept.

First, considering Hippocrates's recommendation "first, do no harm," known to all physicians, it is possible to see sensible medicine as a modern version of the principle of first, do no harm with its nonpassive aspect; it adds good care and good evaluation to the process as a good course of action for the patient. In this context, it should be emphasized that providing good care and maintaining good evaluation processes, instead of worsening the current situation, constitutes a mode of action seeking moderate and humble good with the possibilities provided by modern medicine. In other words, sensible medicine assumes that a physician who does not give the impression of proactively seeking the right course of action is, in fact, actively seeking the right course. In this context, physicians can comprehend that they are in action seeking the good despite prejudice and extreme expectations.

Second, the attribution of concepts, such as health army and warrior $^{1}$, attributed to healthcare workers regarded as representations of social reality ${ }^{1}$, and sensible medicine is a search for a balance between hawkish action and nihilism leading to inaction, as the authors pointed out. ${ }^{3}$ Thus, the physician's motives arising from both being an individual and being a physician should be considered. We believe that the virtues Aristotle attributed to individuals are valuable in discussing this concept. Considering the current warrior analogies, what is interesting in our opinion is the benefit of remembering the virtues Aristotle attributed to warriors or soldiers. The concept of sensible medicine may remind us of the moderation between boldness and cowardice, which Aristotle described as a virtue of a warrior. We characterize this approach as a virtue in the analogy we establish because of the need for thinking about moderation as a personal awareness that balances the unconscious urge to take action as the authors expressed in the context of sensible medicine beyond a purely factual moderation. As a matter of fact, in speaking of valor with reference to soldiers, Aristotle relies on excessive self-confidence and fear, and he speaks of the importance of a calm approach that considers fear rather than excessive self-confidence. He does not consider an immoderation that endangers one's life for small achievements as a good military trait. ${ }^{4}$

In this regard, moderation against our desire to take action can be considered a virtue associated with sensible medicine. An insight that is gained through education in relation to moderation, particularly in emergency and uncertain situations, can be associated with the concept of sensible medicine as a virtue for restraining the physician in taking unconscious action albeit for the better. In the final analysis, it is crucial for the physician, who is a moral subject, to find a measure between nihilism (inaction) and excessive aggressive action in the context of sensible medicine. Therefore, if an action is reasonable according to a fact based on knowledge, it will be performed, and if not, it will be postponed.

Although sensible medicine appears to focus on a rational action and result, it is fundamentally developed on a virtue, which can

In this article, we exclude the veracity or inaccuracy of phrases, such as warrior and health army, by placing them in bracket 
be described as moderation. Considering how Aristotle perceived human action and thought, the reason involving activity includes the possibility to improve even in relatively adverse situations. ${ }^{5}$ As such, sensible medicine also means taking the optimal course in emergencies, and in this sense, the word sensible in the phrase sensible medicine is valuable.

Finally, establishing a relationship with the concept of sensible medicine in terms of ethical principles that gather different approaches and guide physicians with regard to actions in medicine seems possible. In this sense, it is possible to say that the sensible medicine approach has a strong ethical reference in emergency and uncertain situations in terms of maintaining a balance between benefit and harm.

In conclusion, it can be stated that adopting the sensible medicine approach regarding intense social expectations and pressures as well as (new) knowledge bombardment have strong philosophical and ethical bases in emergencies without sufficient informational evidence.
Author Contributions: Concept - A.Y., B.A.; Design - A.Y., B.A.; Analysis and/or Interpretation - A.Y., B.A.; Literature Review - A.Y., B.A.; Writing - A.Y., B.A.; Critical Review - B.A

Conflict of Interest: The authors have no conflicts of interest to declare.

Funding: The authors declared that this study has received no financial support.

\section{REFERENCES}

1. Gupta B, Jit S, Bajwa S, Malhotra N, Mehdiratta L, Kakkar K. Tough times and miles to go before we sleep-Corona warriors. Indian J Anaesth. 2020;64(14(Suppl S2)):120-124. [Crossref]

2. Venuleo C, Marinaci T, Gennaro A, Palmieri A. The meaning of living in the time of COVID-19. A large sample narrative inquiry. Front Psychol. 2020;11:577077. [Crossref]

3. Seymour CW, McCreary EK, Stegenga J. Sensible medicine-balancing intervention and inaction during the COVID-19 pandemic. JAMA. 2020;324(18):1827-1828. [Crossref]

4. Aristoteles. Nicomachean Ethics (Nikomakhos'a Etik). 5th ed. Ankara: BilgeSu Yayıncılık; 2014 (in Turkish).

5. Lawrence G. Human good and human function. In: Kraut R, editor. The Blackwell guide to Aristotle's Nicomachean Ethics. Oxford: Blackwell Publishing; 2006:59. 